\title{
Effect of magnetic nanoparticles on apoptosis and cell cycle induced by wogonin in Raji cells
}

This article was published in the following Dove Press journal:

International Journal of Nanomedicine

13 February 2012

Number of times this article has been viewed

\begin{tabular}{|c|}
\hline Lei Wang ${ }^{1,2, *}$ \\
\hline Haijun Zhang ${ }^{1,2, *}$ \\
\hline Baoan Chen ${ }^{1,2}$ \\
\hline Guohua Xia ${ }^{1,2}$ \\
\hline Shuai Wang ${ }^{1,2}$ \\
\hline Jian Cheng ${ }^{1,2}$ \\
\hline Zeye Shao $^{1,2}$ \\
\hline Chong Gao \\
\hline Wen Bao ${ }^{1,2}$ \\
\hline Liang Tian ${ }^{1,2}$ \\
\hline Yanyan Ren ${ }^{1,2}$ \\
\hline Peipei $X u^{1,2}$ \\
\hline Xiaohui Cai ${ }^{1,2}$ \\
\hline Ran Liu ${ }^{1,2}$ \\
\hline Xuemei Wang ${ }^{3}$ \\
\hline $\begin{array}{l}\text { 'Department of Hematology } \\
\text { and Oncology, Zhongda Hospital, } \\
\text { Medical School, }{ }^{2} \text { Faculty of Oncology, } \\
\text { Medical School, }{ }^{3} \text { State Key Laboratory } \\
\text { of Bioelectronics (Chien-Shiung Wu } \\
\text { Laboratory), Southeast University, } \\
\text { Nanjing, China }\end{array}$ \\
\hline
\end{tabular}
to this work

\begin{abstract}
Traditional Chinese medicine is gradually becoming a new source of anticancer drugs. One such example is wogonin, which is cytotoxic to various cancer cell lines in vitro. However, due to its low water solubility, wogonin is restricted to clinical administration. Recently, the application of drug-coated magnetic nanoparticles (MNPs) to increase water solubility of the drug and to enhance its chemotherapeutic efficiency has attracted much attention. In this study, wogonin was conjugated with the drug delivery system of MNPs by mechanical absorption polymerization to fabricate wogonin-loaded MNPs. It was demonstrated that MNPs could strengthen wogonin-induced cell inhibition, apoptosis, and cell cycle arrest in Raji cells by methylthiazol tetrazolium assay, flow cytometer assay, and nuclear 4',6-diamidino2-phenylindole staining. Furthermore, the molecular mechanisms of these phenomena were explored by western blot, in which the protein levels of caspase 8 and caspase 3 were increased significantly while those of survivin and cyclin E were decreased significantly in wogonin-MNPs group. These findings suggest that the combination of wogonin and MNPs provides a promising strategy for lymphoma therapy.
\end{abstract}

Keywords: wogonin, magnetic nanoparticles, Raji cell, apoptosis, cell cycle, caspase 8, caspase 3, survivin, cyclin E

\section{Introduction}

Lymphoma is a refractory malignant tumor that originates in the lymphatic system. The two main types are Hodgkin's lymphoma and non-Hodgkin's lymphoma (NHL). Statistics show that there were about 74,030 cases of lymphoma diagnosed in the US, including 8490 Hodgkin's lymphoma and 65,540 NHL in 2010. With poor treatment outcomes, NHL is the eighth leading cause of cancer-related death in males and the sixth in females in the US. ${ }^{1}$ The standard chemotherapy regimen of NHL is cyclophosphamide, doxorubicin, vincristine, and prednisone, which plays an important role in the treatment of NHL. Unfortunately, a considerable number of patients undergoing cyclophosphamide, doxorubicin, vincristine, and prednisone relapse thereafter or suffer from dose-related side effects and complications. Furthermore, stem cell transplantation, as a treatment of curing $\mathrm{NHL},{ }^{2}$ is too expensive for patients, so curative treatment can be achieved in only a minority of NHL patients. Thus, novel therapeutic strategies are urgently needed to improve palliative treatment, prolong life expectancy, and improve quality of life in patients with lymphoma.

Wogonin (5,7-dihydroxy-8-methoxyflavone; Figure 1), isolated from the roots of the traditional Chinese herb Scutellaria baicalensis Georgi, has been recently recognized as a new anticancer drug that possesses cytotoxic effect against a large panel
Correspondence: Baoan Chen Department of Hematology, Zhongda Hospital, Medical School, Southeast University, Nanjing 210009, China

Tel +862583272006

Fax+8625832720II

Email cba8888@hotmail.com 

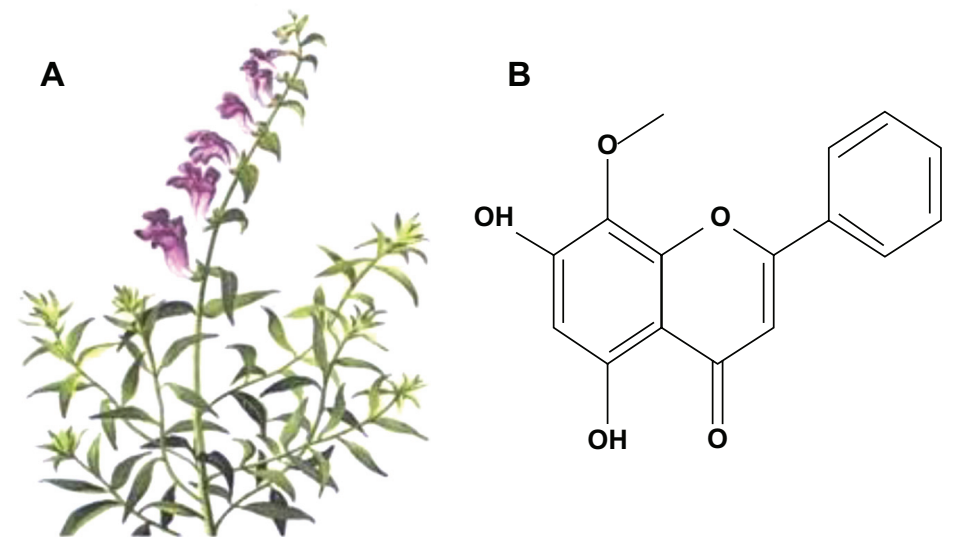

Figure I Structure of wogonin derived from Scutellaria baicalensis Georgi. (A) S. baicalensis Georgi; (B) molecular structure of wogonin.

of human cancer cell lines by inducing apoptosis in vitro. ${ }^{3-5}$ Accumulating evidence demonstrates that wogonin also dramatically inhibits the development and growth of tumors in vivo. ${ }^{6}$ Notably, it has also been reported that wogonin has no or very low toxicity to nonmalignant cells. ${ }^{7}$ However, its low water solubility remains a problem, and the healing mechanisms of wogonin are still not fully known.

What's exciting is that advances in nanotechnology have provided an innovative paradigm to overcome the problems of cancer diagnosis and therapy. Due to large surface-to-volume ratio, biodegradable nature, biocompatibility, low toxicity, and superparamagnetic property, magnetic nanoparticles (MNPs) can not only be used as a diagnostic tool, ${ }^{8}$ but also offer the capabilities of cancer therapeutics. ${ }^{9}$ Apart from improving drug solubility, ${ }^{10}$ site-specific drug delivery, ${ }^{11}$ and magnetic hyperthermia, ${ }^{12}$ it was proposed that high doses of iron oxide nanoparticles on their own may generate local oxidative stress for cancer therapy. ${ }^{13}$

In the present study, a wogonin-MNPs drug delivery system was uploaded for tumor therapy with higher efficiency, and the underlying mechanisms were further investigated.

\section{Materials and methods Main materials}

Wogonin (Jiangsu Key Lab Carcinogenesis and Intervention, China Pharmaceutical University, Nanjing, China) was dissolved in dimethyl sulfoxide (Sigma-Aldrich Corporation, St Louis, $\mathrm{MO}$ ), stored at $-20^{\circ} \mathrm{C}$, and then diluted in Gibco $^{\circledR}$ Roswell Park Memorial Institute 1640 medium (Invitrogen Life Technologies, Carlsbad, CA) with 10\% fetal bovine serum (Sijiqing Biological Engineering Materials Co, Ltd, Hangzhou, China); the final concentration of dimethyl sulfoxide was less than $0.15 \%$, which did not show toxicity against Raji cells. ${ }^{14}$ Ferric chloride $\left(\mathrm{FeCl}_{3} \cdot 6 \mathrm{H}_{2} \mathrm{O}\right)$, ferrous chloride $\left(\mathrm{FeCl}_{2} \cdot 4 \mathrm{H}_{2} \mathrm{O}\right), 25 \%$ ammonia solution, and citric acid monohydrate were purchased from Sinopharm Chemical Reagent Co, Ltd, (Shanghai, China); methylthiazol tetrazolium (MTT) from Sigma-Aldrich; Annexin V-fluorescein isothiocyanate Apoptosis Detection Kit and Cell Cycle Detection Kit from KeyGen Biotech Co, Ltd, (Nanjing, China); 4, 6-diamidino-2-phenylindole (DAPI) from Beyotime Institute of Biotechnology (Haimen, China); and monoclonal antibodies, including caspase 3, caspase 8, survivin and cyclin E, were supplied by Santa Cruz Biotechnology (Santa Cruz, CA).

\section{Synthesis of MNPs}

MNPs (magnetite $\mathrm{Fe}_{3} \mathrm{O}_{4}$ ) were prepared by coprecipitation of $\mathrm{FeCl}_{3}$ and $\mathrm{FeCl}_{2}$ (2:1 molar ratio) in an alkali ammonia solution. Briefly, $2.61 \mathrm{~g}$ of $\mathrm{FeCl}_{3} \cdot 6 \mathrm{H}_{2} \mathrm{O}$ and $1.04 \mathrm{~g}$ of $\mathrm{FeCl}_{2} \cdot 4 \mathrm{H}_{2} \mathrm{O}$ were mixed in $100 \mathrm{~mL}$ of demineralized water in a three-necked flask under a nitrogen atmosphere and the temperature was increased to $80^{\circ} \mathrm{C}$. With constant mechanical stirring, $10 \mathrm{~mL}$ of ammonia solution was introduced slowly to the reaction mixture and the same temperature was maintained for another 30 minutes. The precipitates were washed several times with demineralized water by magnetic separation. Thereafter, $1.37 \mathrm{~g}$ of citric acid was added to magnetic fluid sample and heated to $90^{\circ} \mathrm{C}$ under continuous stirring for 90 minutes. The black precipitates were obtained by cooling to room temperature and then subjected to dialysis against demineralized water in an $8-14 \mathrm{kD}$ cutoff cellulose membrane for 48 hours to remove excess unbound citric acid. Finally, the products were lyophilized and stored in a $4^{\circ} \mathrm{C}$ refrigerator.

\section{Preparation of wogonin-MNPs as a drug delivery system}

Before application in the present experiment, $10 \%$ inactivated fetal bovine serum was added to the prepared 
MNPs - well distributed in fresh Roswell Park Memorial Institute 1640 medium - by using ultrasound treatment to obtain a MNP colloidal suspension, as previously reported..$^{15}$ Various concentrations of wogonin were then conjugated with $80 \mathrm{mg} / \mathrm{L}$ MNPs by mechanical absorption polymerization at $4{ }^{\circ} \mathrm{C}$ for 48 hours, which did not show toxicity against Raji cells.

\section{Cell line and cell culture}

NHL cell line Raji was obtained from Jiangsu Institute of Hematology (Suzhou, China). The cells were cultured in Roswell Park Memorial Institute 1640 with 10\% fetal bovine serum, $100 \mathrm{U} / \mathrm{mL}$ penicillin, and $100 \mu \mathrm{g} / \mathrm{mL}$ streptomycin at $37^{\circ} \mathrm{C}$ in a $5 \%$ carbon dioxide humidified environment. The cells in logarithmic growth phase were used in all experiments.

\section{MTT assay}

Raji cells $\left(1 \times 10^{4}\right.$ cells per well $)$ were incubated with either MNPs, wogonin, or wogonin-MNPs in 96-well plates for 24, 48, and 72 hours; $20 \mu \mathrm{L}$ of MTT solution ( $5 \mathrm{mg} / \mathrm{mL}$ ) was added to each well at $37^{\circ} \mathrm{C}$ in the dark for 4 hours. The formazan crystals were solubilized in $200 \mu \mathrm{L}$ of dimethyl sulfoxide in every well, followed by reading the absorbance at $570 \mathrm{~nm}$ using a plate reader (Model 550 Microplate Reader; Bio-Rad Laboratories, Tokyo, Japan). Cell viability (\%) was expressed as: $\mathrm{OD}_{\text {test cells }} / \mathrm{OD}_{\text {control cells }} \times 100$, where OD represents optical density. Cell inhibition rate (\%) was determined as follows: $\left(1-\mathrm{OD}_{\text {test cells }} / \mathrm{OD}_{\text {control cells }}\right) \times 100$. Each assay was repeated at least three independent times.

\section{Cell cycle analysis}

After treatment for 48 hours, the cells were collected by centrifugation (LD25-Z low speed auto balancing centrifuge; Beijing Medical Centrifuge Plant, Beijing, China) at $1500 \mathrm{rpm}$ for 5 minutes and washed with ice-cold phosphate buffered saline, and stained with propidium iodide and ribonuclease for $30 \mathrm{~min}$ utes. The cell cycle was analyzed by flow cytometer (FACSCalibur flow cytometer; BD Biosciences, San Jose, CA).

\section{Apoptosis assay}

After 48 hours incubation in the medium containing different drugs at $37^{\circ} \mathrm{C}$, Raji cells were collected and washed twice with phosphate buffered saline and centrifuged at $2000 \mathrm{rpm}$ for 5 minutes. The cells were then suspended in $500 \mu \mathrm{L}$ binding buffer and $5 \mu \mathrm{L}$ Annexin V-fluorescein isothiocyanate, and incubated for 15 minutes at room temperature in the dark. The apoptotic cells were analyzed by flow cytometer with CellQuest ${ }^{\mathrm{TM}}$ software (FACSCalibur; BD Biosciences). Both early (Annexin V-positive, propidium iodide-negative) and late (Annexin V-positive, propidium iodide-negative) apoptotic cells were included in cells death determinations.

\section{DAPI staining}

Raji cells were treated for 48 hours, collected, and smeared. The cells were then fixed with methanol for 10 minutes and stained with DAPI for 15 minutes. Thereafter, the cells were observed under fluorescence microscope $(B \times 51$ EpiFluorescence Microscope; Olympus, Tokyo, Japan).

\section{Western blot analysis}

After experimental treatment, total protein was isolated on ice and subjected to $10 \%$ sodium dodecyl sulfate polyacrylamide gel electrophoresis gels using modified radio immunoprecipitation assay buffer, and then transferred to a polyvinylidene difluoride membrane (65421; Pall Corporation, Port Washington, NY). The blots were stained with primary monoclonal antibodies, either anti-caspase 3, caspase 8, survivin, or cyclin E overnight at $4^{\circ} \mathrm{C}$, and then with horseradish peroxidase conjugated goat anti-rabbit or mouse secondary antibody for 1 hour at room temperature. The protein bands were detected with an Amersham enhanced chemiluminescence detection system (RPN2135; GE Healthcare Life Sciences, Little Chalfont, UK). After normalization by the corresponding expression of $\beta$-actin, protein expression levels were determined by densitometry scans (Photoshop CS5 Extended, Adobe Systems Inc, San José, CA).

\section{Statistical analysis}

Data were expressed as mean \pm standard deviation from triplicate experiments and analyzed with IBM SPSS (v 13.0; SPSS Inc, Chicago, IL). Differences were evaluated using one-way analysis of variance or Student's $t$-test. $P<0.05$ was considered statistically significant.

\section{Results}

\section{Characterization of MNPs}

The magnetic iron oxide nanoparticles with a spherical shape had an average size of $18 \mathrm{~nm}$ determined by transmission electron microscope (Figure 2A). As shown in Figure 2B, the diameter of MNPs ranged from $5 \mathrm{~nm}$ to $30 \mathrm{~nm}$. The hydrodynamic diameter of the citric acid-coated magnetic particles was $38.9 \pm 1.2 \mathrm{~nm}$ with a narrow polydispersity $(0.293 \pm 0.007)$ based on photon correlation spectroscopy (Nicomp 380; Particle Sizing Systems, Santa Barbara, CA) (Figure 2C). In the present study, citric acid-coated MNPs did not settle down under the influence of the magnet, suggesting that the colloidal solution was stable. It was also observed that wogonin did not precipitate in the colloidal suspension 


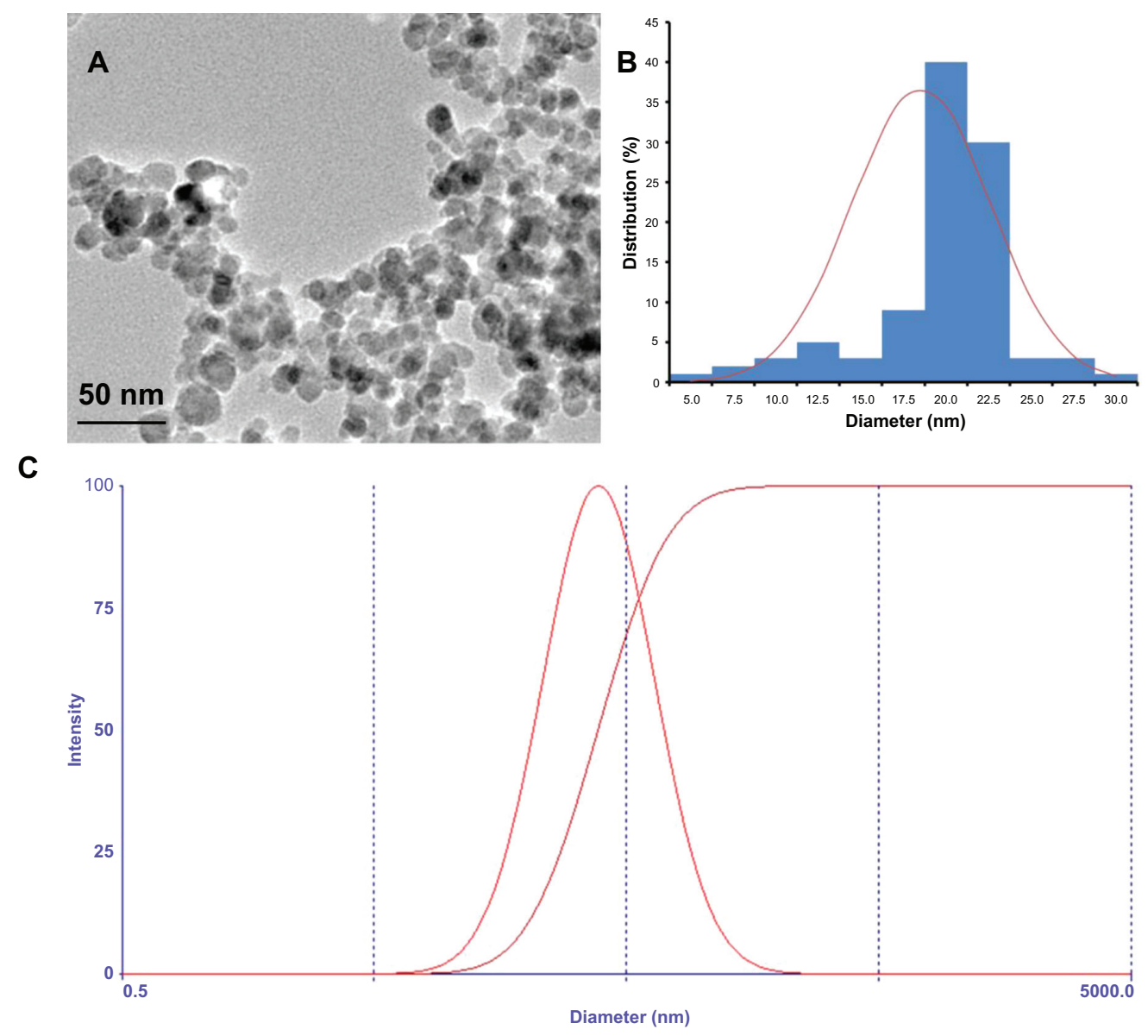

Figure 2 Physical characteristic of the citric acid-coated magnetic particles. (A) Transmission electron microscopic images of magnetic nanoparticles; (B) size distribution histogram of magnetic nanoparticles; (C) hydrodynamic particle size distribution of citric acid-coated magnetic particles.

of the wogonin-MNPs drug delivery system after 2 months of storage, which indicates that the solubility of wogonin was improved by MNPs.

\section{Cell growth inhibition}

MTT assays were carried out to explore cell viability and inhibition rate of lymphoma cancer cells after being coincubated with different concentrations of wogonin or wogoninMNPs with equivalent wogonin concentration for 24,48 , and 72 hours. As shown in Figures 3 and 4, results suggest that wogonin-MNPs could inhibit growth of Raji cells more effectively than wogonin alone $(P<0.05)$. Notably, there was no significant difference between MNPs alone and control group $(P>0.05)$, which confirmed their low cytotoxicity.

\section{Cell cycle arrest}

The effects of MNPs, wogonin, and wogonin-MNPs on the cell cycle were investigated by flow cytometry at 48 hours. Results showed an increased amount of the cell population in $G_{0} / G_{1}$ phase. Notably, the shift of cell distribution into the $\mathrm{G}_{0} / \mathrm{G}_{1}$ phase was increased in a dose-dependent manner and augmented by
MNPs (Figure 5; Table 1). There was no significant difference between MNPs alone and control group $(P>0.05)$.

\section{Enhancement of apoptosis}

Apoptotic rates of Raji cells were examined with Annexin V propidium iodide double-staining assay. Flow cytometry results show that the proportion of apoptotic cells in wogoninMNPs group increased significantly compared with that in wogonin group $(P<0.05)$. However, there was no significant difference between MNPs alone and control group $(P>0.05)$ (Figure 6). Notably, apoptotic rates in Raji cells treated with wogonin increased in a dose-dependent manner, which were higher when combined with MNPs. All these results further strengthen the possibility that MNPs could strengthen the effect of wogonin on cell apoptosis.

\section{Morphologic characterization of apoptosis}

Nucleolus changes of Raji cells under fluorescence microscope are shown in Figure 7. Raji cells with equably blue fluorescence in MNPs alone and control group demonstrated that chromatin 


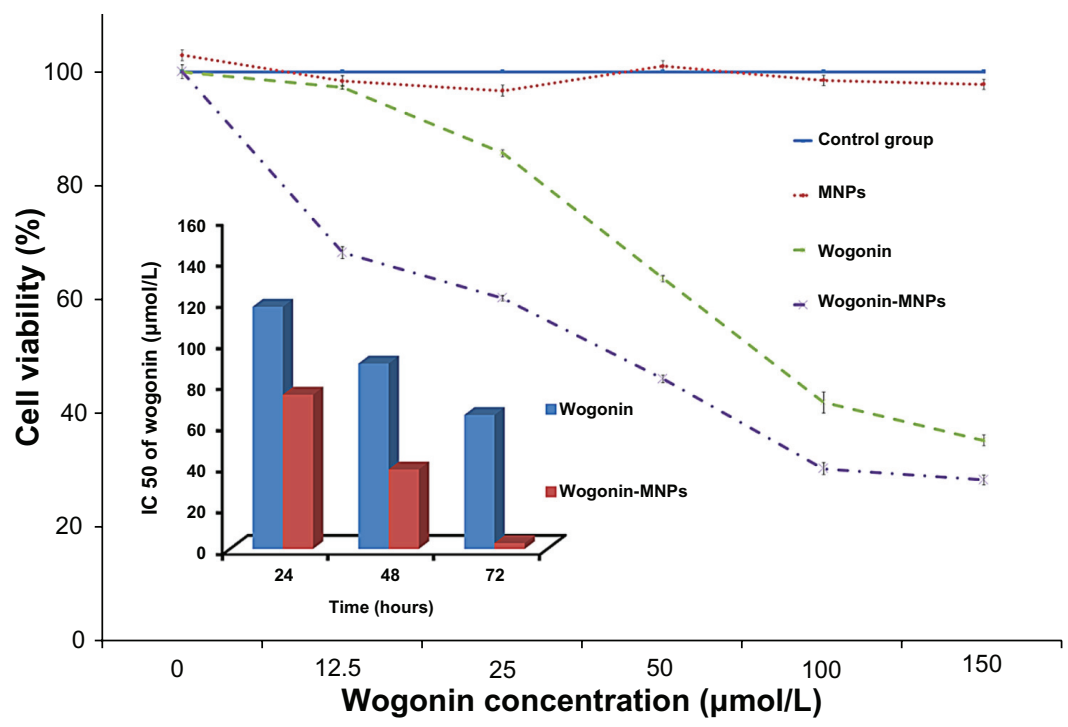

Figure 3 Viability of Raji cells treated with magnetic nanoparticles, wogonin, or wogonin-magnetic nanoparticles for 48 hours by methylthiazol tetrazolium assay. Inset: Comparison of the half maximal inhibitory concentration of wogonin and wogonin-magnetic nanoparticles at different culture times for Raji cells. Abbreviations: MNPs, magnetic nanoparticles; $I C_{50}$, half maximal $(50 \%)$ inhibitory concentration.

equably distributed in the nucleolus. However, after treatment with various concentrations of wogonin and wogonin-MNPs, Raji cells displayed the typical features of apoptosis, such as chromatin condensation, nucleolus pyknosis, nuclear fragmentation, and apoptotic bodies. Notably, it was more evident that the features of apoptosis in the cells incubated with wogoninMNPs were observed compared to wogonin alone.

\section{Expression of caspase 3, caspase 8, survivin, and cyclin $\mathrm{E}$}

Based on computer-assisted image analysis, it was demonstrated that survivin, caspase 3 , and caspase 8 proteins in Raji cells treated with $80 \mathrm{mg} / \mathrm{L}$ MNPs for 48 hours had no significant changes when compared with control group $(P>0.05)$. However, caspase 3 and caspase 8 expression
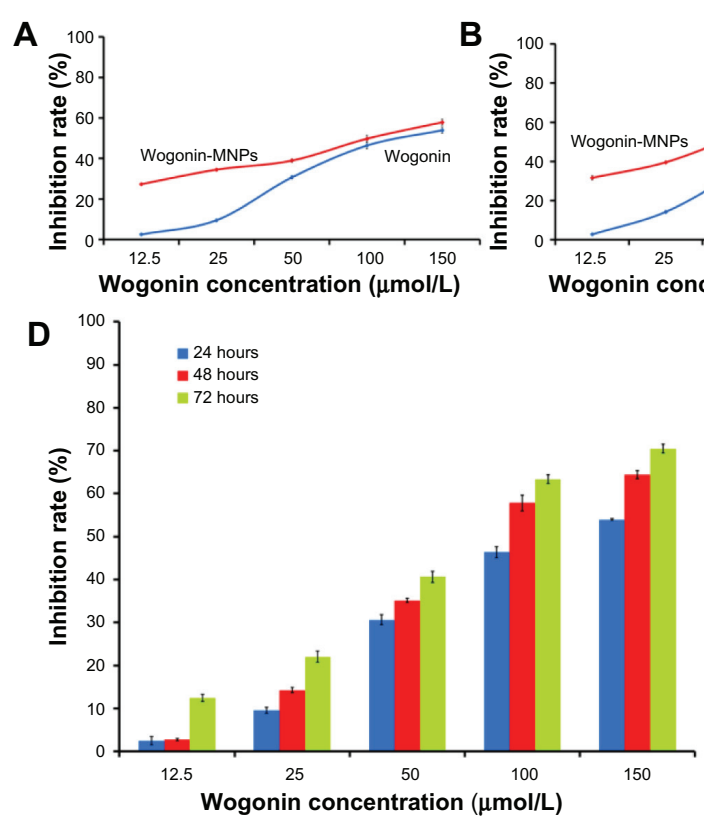
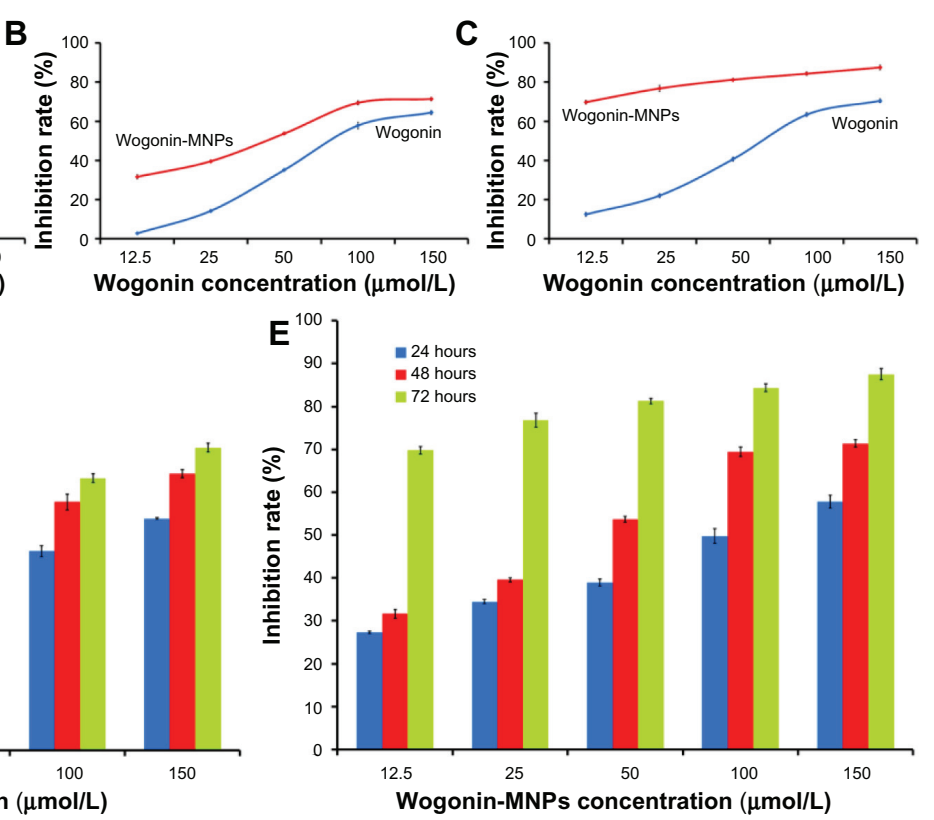

Figure 4 Inhibition rates of Raji cells treated with different concentrations of wogonin or wogonin-magnetic nanoparticles for 24,48 , and 72 hours. (A) Inhibition rates of Raji cells treated with different concentrations of wogonin or wogonin-magnetic nanoparticles for 24 hours; (B) inhibition rates of Raji cells treated with different concentrations of wogonin or wogonin-magnetic nanoparticles for 48 hours; (C) inhibition rates of Raji cells treated with different concentrations of wogonin or wogonin-magnetic nanoparticles for 72 hours; (D) inhibition rates of Raji cells treated with different concentrations of wogonin for 24, 48, and 72 hours; (E) inhibition rates of Raji cells treated with different concentrations of wogonin-magnetic nanoparticles for 24, 48, and 72 hours.

Abbreviation: MNPs, magnetic nanoparticles. 


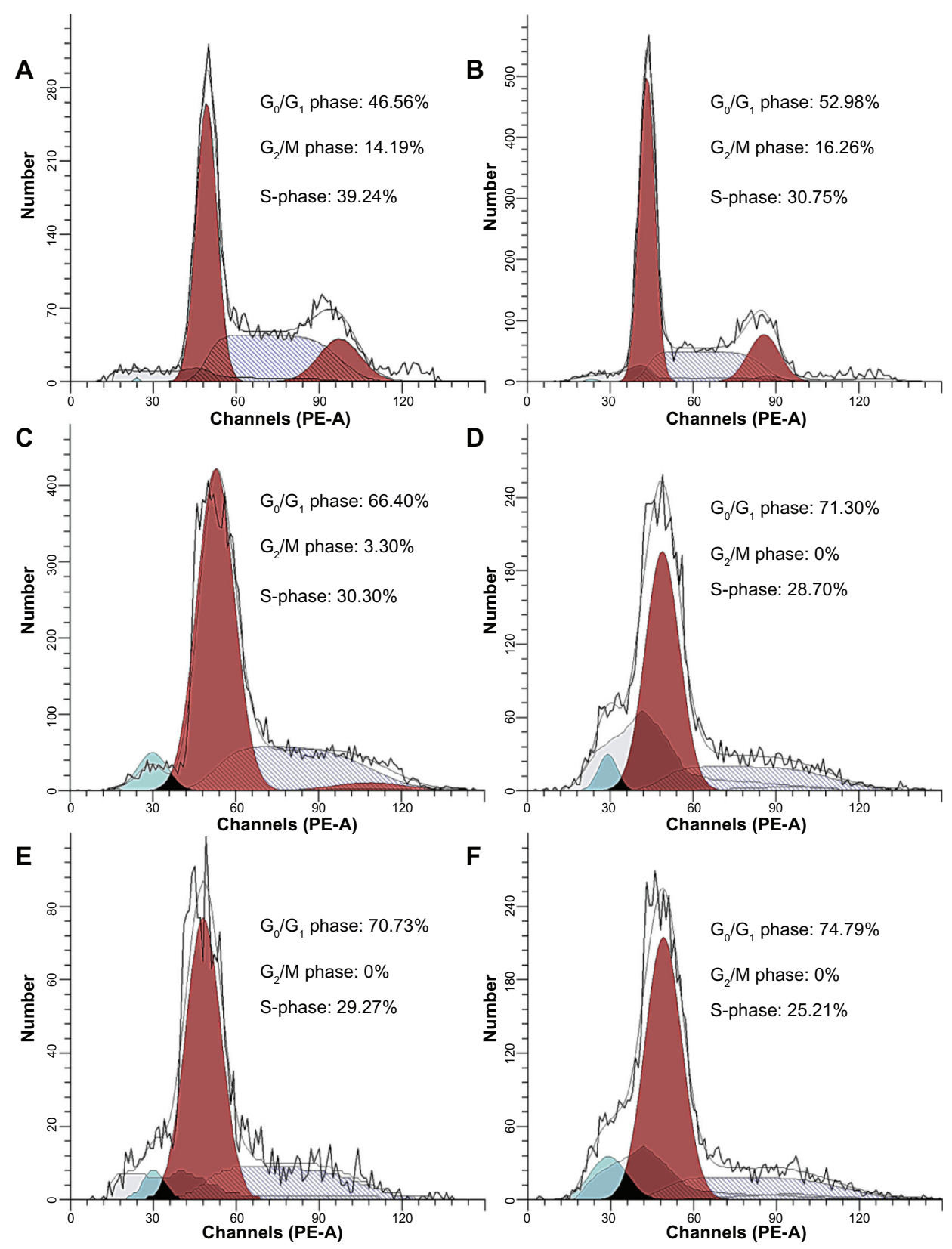

Figure 5 Cell cycle distributions of Raji cells treated with wogonin or wogonin-magnetic nanoparticles for 48 hours. (A) Control group; (B) 80 mg/L magnetic nanoparticles; (C) $12.5 \mu \mathrm{mol} / \mathrm{L}$ wogonin; (D) $12.5 \mu \mathrm{mol} / \mathrm{L}$ wogonin-magnetic nanoparticles; (E) $50 \mu \mathrm{mol} / \mathrm{L}$ wogonin; (F) $50 \mu \mathrm{mol} / \mathrm{L}$ wogonin-magnetic nanoparticles.

Abbreviation: MNPs, magnetic nanoparticles.

in Raji cells treated with either wogonin or wogonin-MNPs for 48 hours were upregulated compared with MNPs alone $(P<0.05)$. The level of survivin was downregulated in wogonin group, and this downregulation was further augmented in wogonin-MNPs group. In addition, the expression of cyclin $\mathrm{E}$, which did not significantly change when Raji cells were treated with wogonin alone $(P>0.05)$, was dramatically downregulated in Raji cells treated with wogonin-MNPs compared with other groups $(P<0.05)$ (Figure 8).

\section{Discussion}

The high toxicity of anticancer drugs to normal tissues is the biggest obstacle of cancer therapy, which restricts the application of antineoplastics. ${ }^{16}$ Enhancing the efficacy of chemotherapy and ameliorating the side effects of cancer chemotherapies are the major goals in the development of tumor treatment. ${ }^{17}$ With negligible toxicity to nonmalignant cells, ${ }^{7}$ wogonin, a remedy in traditional Chinese medicine, is becoming an attractive candidate for the development of a new anticancer drug. It has been demonstrated that 
Table I Cell cycle distributions of Raji cells

\begin{tabular}{llll}
\hline Group & \multicolumn{3}{l}{ Cell cycle phase } \\
\cline { 2 - 4 } & $\mathbf{G}_{0} / \mathbf{G}_{\mathbf{I}}$ & $\mathbf{G}_{2} / \mathbf{M}$ & $\mathbf{S}$ \\
\hline Control group & $46.27 \pm 1.36$ & $14.88 \pm 0.6 \mathrm{I}$ & $38.85 \pm 1.52$ \\
$80 \mathrm{mg} / \mathrm{L} \mathrm{MNPs}$ & $52.69 \pm 2.16$ & $16.15 \pm 0.28$ & $31.16 \pm 1.91$ \\
$12.5 \mu \mathrm{mol} / \mathrm{L}$ wogonin & $66.90 \pm 2.32$ & $2.37 \pm 0.93$ & $30.73 \pm 1.87$ \\
$50 \mu \mathrm{mol} / \mathrm{L}$ wogonin & $70.58 \pm 0.98$ & 0 & $29.41 \pm 0.98$ \\
$12.5 \mu \mathrm{mol} / \mathrm{L}$ wogonin-MNPs & $71.58 \pm 0.77$ & 0 & $28.42 \pm 0.77$ \\
$50 \mu \mathrm{mol} / \mathrm{L}$ wogonin-MNPs & $75.12 \pm 1.63$ & 0 & $24.88 \pm 1.63$ \\
\hline
\end{tabular}

Note: Mean \pm standard deviation, $\%$.

Abbreviation: MNPs, magnetic nanoparticles.

wogonin possesses a direct cytotoxicity to a large panel of human malignant cell lines in vitro ${ }^{3-5}$ and suppresses tumor growth in vivo. ${ }^{6}$ Outcomes in the present study indicate that wogonin can inhibit the growth of Raji cells in a dose- and time-dependent manner. However, the current barrier to clinical application of wogonin is its low water solubility $(<100 \mu \mathrm{mol} / \mathrm{L})$, which was observed in the present experiment.

A

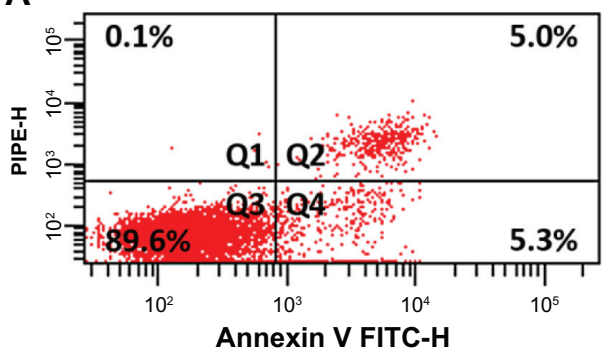

C

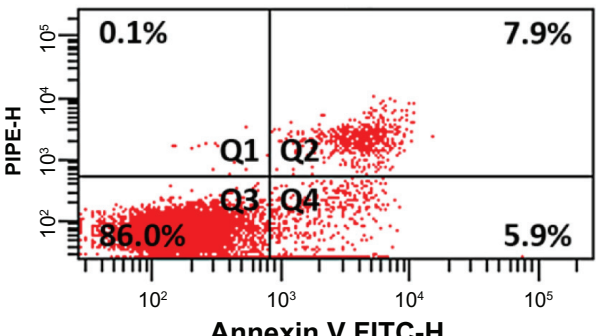

Annexin V FITC-H

E

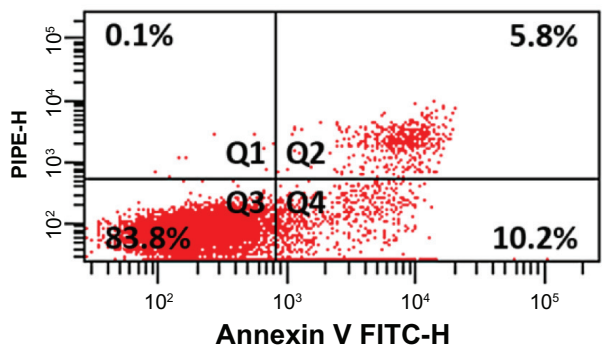

In order to overcome such limitation, many strategies, such as delivery of drugs by nanocarriers, have been designed to solve problems exhibited by conventional "free" drugs, including limited stability, poor solubility, rapid clearing, and, in particular, lack of selectivity. ${ }^{18}$ With satisfactory chemical stability, favorable toxicity profile, and superparamagnetic property, the use of MNPs has emerged as an innovative theranostic. ${ }^{19-21}$ However, large surface-to-volume ratio and magnetic property of iron oxide nanoparticles in nature make them aggregate in aqueous media, seriously impeding their biomedical application. ${ }^{22}$ Citric acid, as a stabilizer, not only makes MNPs stable in biological liquids but also provides the uncoordinated carboxyl groups for further functionalization. ${ }^{23}$ Thus, citric acid-modified MNPs were fabricated. Under the influence of a magnet, MNPs were not observed to settle down, which confirmed the stability of the colloidal solution. One of the most important factors that determines biomedical applications of MNPs is hydrodynamic size. MNPs $<10 \mathrm{~nm}$ are subject to tissue

B

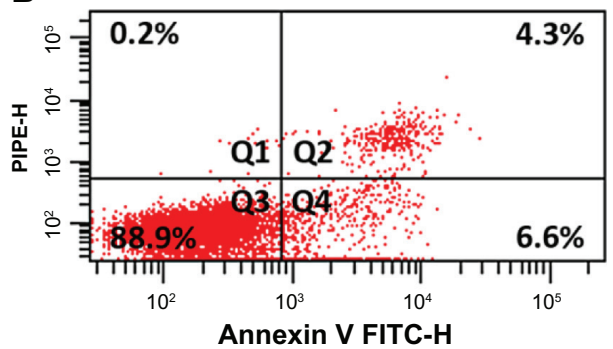

D

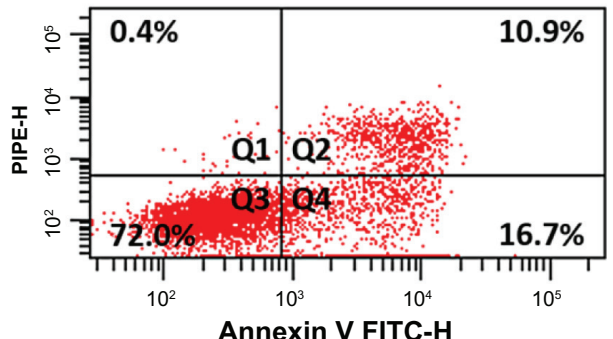

$\mathbf{F}$

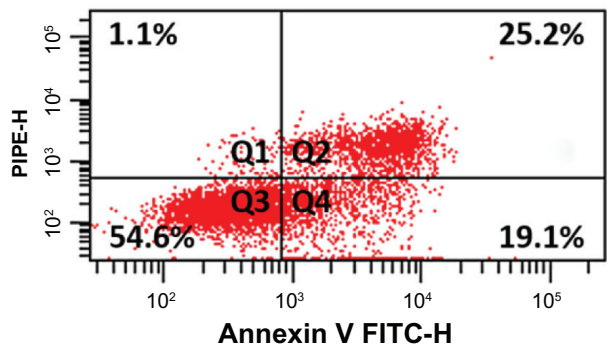

Figure 6 Apoptotic rates of Raji cells treated with magnetic nanoparticles, wogonin, or wogonin-magnetic nanoparticles for 48 hours. (A) Control group; (B) 80 mg/L magnetic nanoparticles; (C) $12.5 \mu \mathrm{mol} / \mathrm{L}$ wogonin; (D) $12.5 \mu \mathrm{mol} / \mathrm{L}$ wogonin-magnetic nanoparticles; (E) $50 \mu \mathrm{mol} / \mathrm{L}$ wogonin; (F) $50 \mu \mathrm{mol} / \mathrm{L}$ wogonin-magnetic nanoparticles. Abbreviations: FITC-H, peak height of fluorescein isothiocyanate channel; MNPs, magnetic nanoparticles; PI, propidium iodide; PE-H, peak height of phycoerythrin channel; QI, necrosis; Q2, late apoptosis; Q3, healthy cells; Q4, early apoptosis. 

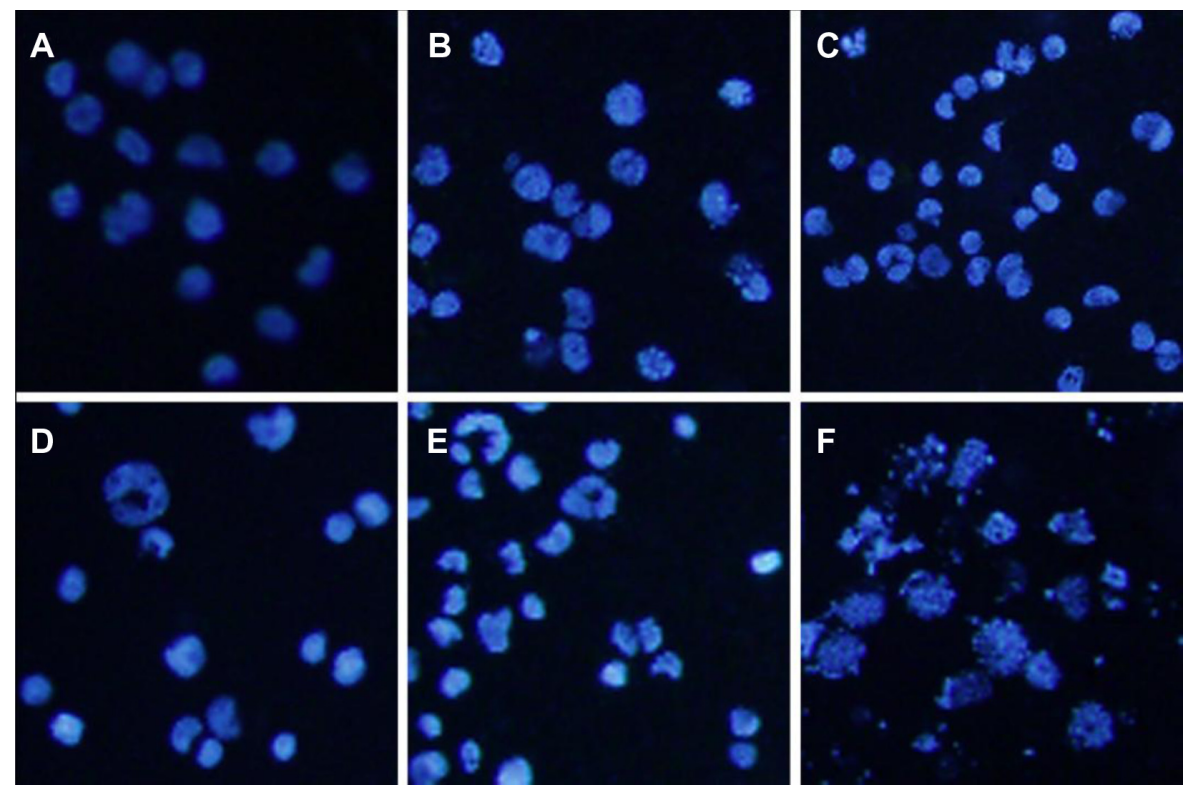

Figure 7 Morphologic characterization of Raji cells after different treatments for 48 hours under inverted fluorescence micrographs (I00×, 4',6-diamidino-2-phenylindole staining). (A) Control group; (B) $80 \mathrm{mg} / \mathrm{L}$ magnetic nanoparticles; (C) $12.5 \mu \mathrm{mol} / \mathrm{L}$ wogonin; (D) $12.5 \mu$ mol/L wogonin-magnetic nanoparticles; (E) $50 \mu \mathrm{mol} / \mathrm{L}$ wogonin; (F) $50 \mu \mathrm{mol} / \mathrm{L}$ wogonin-magnetic nanoparticles.

extravasation and renal clearance, whereas those $>100 \mathrm{~nm}$ are quickly opsoninized and eliminated from circulation via the reticuloendothelial system. ${ }^{19}$ Gupta and Wells ${ }^{24}$ reported that the hydrodynamic diameter of well-designed MNPs ranges from $10 \mathrm{~nm}$ to $100 \mathrm{~nm}$, which is optimal for in vivo applications. In the present study, the fabricated citric acidfunctionalized MNPs, $18 \mathrm{~nm}$ in size, were up to grade and suitable for drug delivery. It was noteworthy that MNPs could not only improve water solubility but also substantially augment the anticancer efficacy of wogonin, especially with a low dose of wogonin or long incubation time; even when the concentration of MNPs was up to $80 \mathrm{mg} / \mathrm{L}$, they showed no obvious toxicity to Raji cells. These results suggest that MNPs are a promising and simple drug carrier for cancer

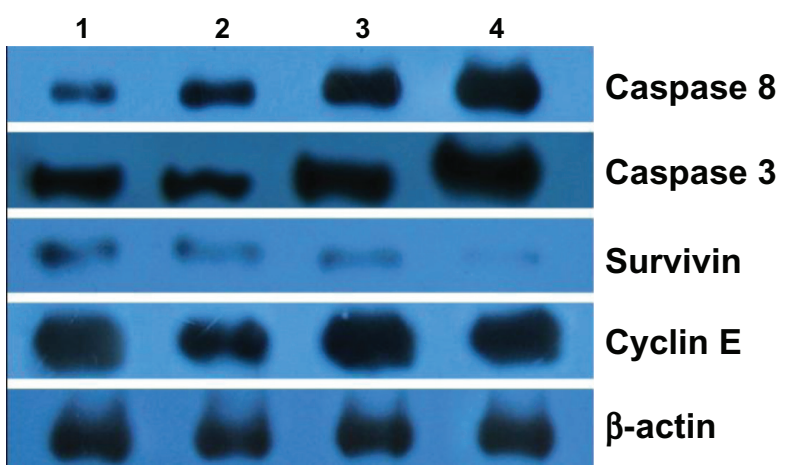

Figure 8 Expression of caspase 3, caspase 8, survivin, and cyclin E protein in Raji cells by western blot after treatment of wogonin with or without magnetic nanoparticles for 48 hours. Lane I, control group; Lane 2, 80 mg/L magnetic nanoparticles; Lane 3, $12.5 \mu \mathrm{mol} / \mathrm{L}$ wogonin; Lane $4,12.5 \mu \mathrm{mol} / \mathrm{L}$ wogonin-magnetic nanoparticles. therapy, which is reinforced by previous studies that demonstrated that intracellular drug concentration could increase via nanoparticle-mediated endocytosis ${ }^{25}$ and that fluctuations in drug levels could be avoided by providing sustained release of drugs to enhance the anticancer efficacy. ${ }^{10}$

The cell cycle is a series of events that take place in a cell leading to its division and duplication. Regulation of the cell cycle involves processes crucial to the survival of a cell. The $\mathrm{G}_{1} / \mathrm{S}$ checkpoint and $\mathrm{G}_{2} / \mathrm{M}$ checkpoint monitor and regulate the progress of the cell cycle, so regulation of the cell cycle is favorable to the treatment of cancer. Recently, Min reported that wogonin exerted potential induction of cycle arrest at $\mathrm{G}_{0} / \mathrm{G}_{1}$ phase in several cancer cell lines. ${ }^{17}$ In the present study, an accumulation of cells in $\mathrm{G}_{0} / \mathrm{G}_{1}$ phase was similarly observed in wogonin-treated Raji cells. Notably, the shift of cell distribution into the $\mathrm{G}_{0} / \mathrm{G}_{1}$ phase was augmented by MNPs. Further studies should be investigated to elucidate the mechanism of the shift.

Cell cycle progress is the result of an orchestrated interaction between several proteins, such as cyclins and cyclindependent kinases, which determine a cell's progress through the cell cycle. It is well known that cyclin D-CDK4/6 complex and cyclin E-CDK2 complex are crucial for $\mathrm{G}_{1}$ checkpoint control. Exposure of different cancer cell lines to wogonin was previously shown to decline cyclin $\mathrm{D}$ protein levels, resulting in growth inhibition at $\mathrm{G}_{0} / \mathrm{G}_{1}$ phase. ${ }^{17}$ Consistent with this notion, an accumulation of cells in the $\mathrm{G}_{0} / \mathrm{G}_{1}$ phase was observed in wogonin-treated Raji cells 
in the present study. Notably, reduced cyclin E protein level was observed in Raji cells treated with wogoninMNPs. These differing results suggest that there may be fundamental differences between cell types. Therefore, wogonin-MNPs possess an enormous potential to evoke cell cycle arrest at $\mathrm{G}_{0} / \mathrm{G}_{1}$ phase via downregulation of cyclin E.

Apoptosis or programmed cell death, which occurs after sufficient cellular damage, is a normal component of the development and health of multicellular organisms. Dysregulation of apoptosis can disrupt the balance between cell growth and cell death and is an important step in the development of cancer. ${ }^{26}$ Evasion of apoptosis has been considered as a hallmark of cancer. ${ }^{27}$ Therefore, activation of apoptosis is more widely used as a potential anticancer strategy. Results in the present study showed that the apoptotic rate of Raji cells treated with wogonin-MNPs increased significantly compared with wogonin alone, suggesting that MNPs synergistically enhance wogonininduced cell apoptosis. Results were also confirmed by the typical morphological features of apoptosis in Raji cells stained with DAPI after treatment with wogonin or wogonin-MNPs.

Apoptotic cell death can be executed by two pathways: the death-receptor pathway (extrinsic pathway) and the mitochondrial pathway (intrinsic pathway). In both pathways, apoptotic death stimulus results in activation of caspases, which are the central executioners of the apoptotic pathway. ${ }^{28,29}$ Initiator caspases, such as caspase 2, 8, 9, 10 , 11 , and 12 initiate disassembly in response to extracellular apoptosis-inducing ligands and are activated in a complex associated with the cytoplasmic death domain of many cell-surface ligand receptors. On the other hand, effector caspases, such as caspase 3, 6, and 7 are then activated by these active initiator caspases through proteolytic cleavage and carry out the cell death program. Thus, caspase 8 and caspase 3 are situated at pivotal junctions in apoptotic pathways. In the present study, a significant increase in the expression of active caspase 8 and caspase 3 protein was observed in Raji cells treated with wogonin and wogonin-MNPs, indicating that the extrinsic pathway is involved in wogonin-induced apoptotic pathways. A recent report suggesting that wogonin could sensitize cancer cells toward TNF $\alpha$-induced apoptosis (extrinsic pathway) $^{30}$ also strengthens the present findings. Moreover, apoptosis is tightly regulated by a fine-tuned balance between proapoptotic and antiapoptotic factors. Survivin, as an inhibitor of apoptosis protein, is not limited to apoptosis inhibition in cancer pathogenesis but is also involved in the regulation of the mitotic spindle checkpoint and the promotion of angiogenesis and chemoresistance. ${ }^{31}$ In the present study, either wogonin alone or wogonin-MNPs increased apoptosis of Raji cells and this was accompanied by the downregulation of survivin protein. In general, wogonin-MNPs induced cell apoptosis through various pathways.

\section{Conclusion}

The present study demonstrates that MNPs not only increase the water solubility of wogonin but also enhance its therapeutic efficiency via blocking the cell cycle at $\mathrm{G}_{0} / \mathrm{G}_{1}$ phase and inducing apoptosis of Raji cells. These findings indicate that the combination of wogonin and MNPs provides a promising strategy for lymphoma therapy.

\section{Acknowledgments}

This work was financially supported by National Key Basic Research Program 973 of China (No 2010CB732404), National Natural Science Funds of People's Republic of China (No 81170492), and Key Medical Disciplines of Jiangsu Province.

\section{Disclosure}

The authors report no conflicts of interest in this work.

\section{References}

1. Jemal A, Siegel R, Xu J, Ward E. Cancer statistics, 2010. CA Cancer J Clin. 2010;60(5):277-300.

2. van Besien K. Current status of allogeneic transplantation for aggressive non-Hodgkin lymphoma. Curr Opin Oncol. 2011;23(6):681-691.

3. Dong $\mathrm{P}$, Zhang Y, Gu J, et al. Wogonin, an active ingredient of Chinese herb medicine Scutellaria baicalensis, inhibits the mobility and invasion of human gallbladder carcinoma GBC-SD cells by inducing the expression of maspin. J Ethnopharmacol. 2011;137(3):1373-1380.

4. Chow SE, Chang YL, Chuang SF, Wang JS. Wogonin induced apoptosis in human nasopharyngeal carcinoma cells by targeting GSK-3 $\beta$ and $\Delta$ Np63. Cancer Chemother Pharmacol. 2011;68(4):835-845.

5. Gao J, Morgan WA, Sanchez-Medina A, Corcoran O. The ethanol extract of Scutellaria baicalensis and the active compounds induce cell cycle arrest and apoptosis including upregulation of p53 and Bax in human lung cancer cells. Toxicol Appl Pharmacol. 2011;254(3):221-228.

6. Yu J, Liu H, Lei J, Tan W, Hu X, Zou G. Antitumor activity of chloroform fraction of Scutellaria barbata and its active constituents. Phytother Res. 2007;21(9):817-822.

7. Lee DH, Kim C, Zhang K, Lee YJ. Role of p53, PUMA, and Bax in wogonin-induced apoptosis in human cancer cells. Biochem Pharmacol. 2008;75(10):2020-2033.

8. Xu H, Cheng L, Wang C, Ma X, Li Y, Liu Z. Polymer encapsulated upconversion nanoparticle/iron oxide nanocomposites for multimodal imaging and magnetic targeted drug delivery. Biomaterials. 2011;32(35):9364-9373.

9. Xia G, Chen B, Ding J, et al. Effect of magnetic $\mathrm{Fe}_{3} \mathrm{O}_{4}$ nanoparticles with 2-methoxyestradiol on the cell-cycle progression and apoptosis of myelodysplastic syndrome cells. Int J Nanomedicine. 2011;6:1921-1927. 
10. Wang C, Zhang H, Chen B, Yin H, Wang W. Study of the enhanced anticancer efficacy of gambogic acid on Capan-1 pancreatic cancer cells when mediated via magnetic $\mathrm{Fe}_{3} \mathrm{O}_{4}$ nanoparticles. Int J Nanomedicine. 2011;6:1929-1935.

11. von Maltzahn G, Park JH, Lin KY, et al. Nanoparticles that communicate in vivo to amplify tumour targeting. Nat Mater. 2011;10(7):545-552.

12. Pradhan P, Giri J, Rieken F, et al. Targeted temperature sensitive magnetic liposomes for thermo-chemotherapy. J Control Release. 2010;142(1):108-121.

13. Foy SP, Labhasetwar V. Oh the irony: iron as a cancer cause or cure? Biomaterials. 2011;32(35):9155-9158.

14. Guevara AP, Vargas C, Sakurai H, et al. An antitumor promoter from Moringa oleifera Lam. Mutat Res. 1999;440(2):181-188.

15. Jiang Z, Chen BA, Xia GH, et al. The reversal effect of magnetic $\mathrm{Fe}_{3} \mathrm{O}_{4}$ nanoparticles loaded with cisplatin on SKOV3/DDP ovarian carcinoma cells. Int J Nanomedicine. 2009;4:107-114.

16. DeVita VT. Dose-response is alive and well. J Clin Oncol. 1986;4(8): 1157-1159.

17. Min LW. New therapeutic aspects of flavones: the anticancer properties of Scutellaria and its main active constituents Wogonin, Baicalein and Baicalin. Cancer Treat Rev. 2009;35(1):57-68.

18. Ashley CE, Carnes EC, Phillips GK, et al. The targeted delivery of multicomponent cargos to cancer cells by nanoporous particle-supported lipid bilayers. Nat Mater. 2011;10(5):389-397.

19. Cole AJ, Yang VC, David AE. Cancer theranostics: the rise of targeted magnetic nanoparticles. Trends Biotechnol. 2011;29(7):323-332.

20. Jang JT, Nah H, Lee JH, Moon SH, Kim MG, Cheon J. Critical enhancements of MRI contrast and hyperthermic effects by dopant-controlled magnetic nanoparticles. Angew Chem Int Ed Engl. 2009;48(7):1234-1238.

21. Comes Franchini M, Baldi G, Bonacchi D, et al. Bovine serum albumin-based magnetic nanocarrier for MRI diagnosis and hyperthermic therapy: a potential theranostic approach against cancer. Small. 2010;6(3):366-370.
22. Goodarzi A, Sahoo Y, Swihart MT, Prasad PN. Aqueous ferrofluid of citric acid coated magnetite particles. Mater Res Soc Symp Proc. 2004;789:661-666.

23. Nigam S, Barick KC, Bahadur D. Development of citrate-stabilized $\mathrm{Fe}_{3} \mathrm{O}_{4}$ nanoparticles: conjugation and release of doxorubicin for therapeutic applications. J Magn Magn Mater. 2011;323(2):237-243.

24. Gupta AK, Wells S. Surface-modified superparamagnetic nanoparticles for drug delivery: preparation, characterization, and cytotoxicity studies. IEEE Trans Nanobioscience. 2004;3(1):66-73.

25. Zhang Y, Kohler N, Zhang M. Surface modification of superparamagnetic magnetite nanoparticles and their intracellular uptake. Biomaterials. 2002;23(7):1553-1561

26. Kerr JF, Winterford CM, Harmon BV. Apoptosis: its significance in cancer and cancer therapy. Cancer. 1994;73(8):2013-2026.

27. Hanahan D, Weinberg RA. Hallmarks of cancer: the next generation. Cell. 2011;144(5):646-674.

28. Nicholson DW. Caspase structure, proteolytic substrates, and function during apoptotic cell death. Cell Death Differ. 1999;6(11):1028-1042.

29. Chen B, Liang Y, Wu W, et al. Synergistic effect of magnetic nanoparticles of $\mathrm{Fe}_{3} \mathrm{O}_{4}$ with gambogic acid on apoptosis of $\mathrm{K} 562$ leukemia cells. Int J Nanomedicine. 2009;4:251-259.

30. Fas SC, Baumann S, Zhu JY, et al. Wogonin sensitizes resistant malignant cells to TNFalpha- and TRAIL-induced apoptosis. Blood. 2006;108(12):3700-3706.

31. Mita AC, Mita MM, Nawrocki ST, Giles FJ. Survivin: key regulator of mitosis and apoptosis and novel target for cancer therapeutics. Clin Cancer Res. 2008;14(16):5000-5005.
International Journal of Nanomedicine

\section{Publish your work in this journal}

The International Journal of Nanomedicine is an international, peerreviewed journal focusing on the application of nanotechnology in diagnostics, therapeutics, and drug delivery systems throughout the biomedical field. This journal is indexed on PubMed Central, MedLine, CAS, SciSearch $\AA$, Current Contents ${ }^{\circledR} /$ Clinical Medicine,

\section{Dovepress}

Journal Citation Reports/Science Edition, EMBase, Scopus and the Elsevier Bibliographic databases. The manuscript management system is completely online and includes a very quick and fair peer-review system, which is all easy to use. Visit http://www.dovepress.com/ testimonials.php to read real quotes from published authors. 